\title{
REFERÊNCIA:
}

MURPHEY, R. M.; PARANHOS da COSTA, M. J. R.; SOUZA LIMA, L. O. de; MOURA DUARTE, F. A. de. Communal suckling in water buffalo (Bubalus bubalis). Applied Animal Behaviour Science, v. 28 , p. $341-352$. 1991.

\section{COMMUNAL SUCKLING IN WATER BUFFALO (Bubalus bubalis)}

Robert M. Murphey ${ }^{1}$; Mateus J. R. Paranhos da Costa ${ }^{2}$; Ligia O. de Souza Lima ${ }^{2}$ and Francisco A. de Moura Duarte ${ }^{3}$

${ }^{1}$ Department of Psychology, University of California, Davis, CA, 95616 (U.S.A.)

${ }^{2}$ Faculdade de Ciências Agrárias e Veterinárias, Universidade Estadual Paulista, 14870 Jaboticabal, São Paulo (Brazil)

${ }^{3}$ Departamento de Genética, Faculdade de Medicina, Universidade de São Paulo, 14049 Ribeirão Preto, São Paulo (Brazil)

(Accepted for publication 6 August 1990)

\begin{abstract}
Murphey, R. M.; Paranhos da Costa, M. J. R.; Lima, L. O. S. and Duarte, F. A. M., 1991. Communal suckling in water buffalo (Bubalus bubalis). Appl. Anim. Behav. Sci., 28: 341-352
\end{abstract}

Communal nursing (an adult female allowing the offspring of another conspecific female to suckle) is a relatively frequent behavior in water buffalo (Bubalus bubalis). Fourteen lactating water buffalo cows and their nursing calves were observed at a Brazilan dairy after the cows had been milked. The two variables of greatest interest were solicitations of their own mothers and other cows by the calves, and acceptances of their own offspring and non-filial calves by the cows. Correlational analyses sugested three easily discriminable clusters of variables. Calves solicited and succeeded in suckling from their own mothers more often than they did their own mothers. They were more likely to try to suckle other cows if they were rejected by their own mothers. Cows that had a high probability of accepting their own offspring tended to accept nonfilial calves as well. Calves tended to maximize the total number rather than the probability of successful solicitations. Communal suckling was not reciprocal. Communal and filial suckling results from encounters between cows and calves performing under different motivational states.

\section{INTRODUCTION}

Communal care or alloparenting is a contribution to the rearing of another individual's progeny by a conspecific (Wilson, 1975; Riedman, 1982; Gittleman, 1985). In addition to presenting a classic theoretical challenge to selection theory, e.g. "Why should an animal invest in resources in promoting the survival of another's offspring...?" (Riedman, 1982), whit the consequent advent of inclusive fitness theory and its attempts to elucidate the bioeconomics of "altruism", communal care and ease of adoption are of practical importance in raising farm animais, especially under conditions of substantial loss of young or their parents.

Communal suckling or nursing as the terms are being used here, refer to an adult female allowing the offspring of another conspecific female to suckle. Giving milk is costly to the donor. Martin (1984) and Mendl and Paul (1989) have pointed out that it should be a useful measure of parental investment. By extension, it should be an especially altruistic act. Communal nursing has 
been observed in several ruminant species, including some domestic livestock (cf. Riedman, 1982). Its spontaneous occurrence is rare in Bos cattle, but can be induced by human intervention (Hudson, 1977; Rosecrans and Hohenboken, 1982; Herd, 1988). It is common knowledge that water buffalo (Bubalus bubalis) often engage in communal nursing, and that they frequently adopt orphans under free-ranging conditions (Tulloch, 1979).

The frequent occurrence of the behavior, the relative immobillty of the animals while exhibiting it, the simplicity of their social organization, the ease of identification of progeny, the large size of the animals, and the relative abundance of them, often in confined spaces under uniform management, make water buffalo excellent subjects for studies of communal nursing. The conditions, above, are met at numerous ranches in Brazil, where the present study took place. In addition, Brazilian water buffalo are descendants of several importations from various sources (Associação Brasileira dos Criadores de Búfalo, undated; das Graças Costa et al., 1971) beginning in the late nineteenth century and probably ending in 1962. The resulting genetic heterogeneity may enhance the generality of observations of Brazilian water buffalo to members of the species in other localities.

The purposes of this study were threefold: (1) to describe relationships between the behavior of cows and calves in dam-offspring and communal nursing; (2) to identify strategies that calves employ in soliciting cows; (3) to assess the extent of reciprocity in the behavior.

\section{ANIMALS, MATERIALS AND METHODS}

The subjects were 14 lactating water buffalo (B. bubalis) cows and their nursing calves. They were River type buffalo with predominantly Murrah Mediterranian phenotypes (cf. Advisory Committee on Technology Innovation, 1981). Cows and their progeny were painted on both sides of the thorax with numbers identifying individual dam-offspring pairs.

The observations took place shortly after morning and afternoon milking sessions (ordenhas) in a Brazilian dairy. The ordenhas were conducted in the same general way as those described for Gyr cattle (Bos indicus) in greater detail elsewhere (Murphey and Duarte, 1983) The cows and calves had been separated from one another since the end of the previous ordenha. When the new ordenha began, the cows were tethered in the milking shed while their calves were restrained in a nearby holding pen. Shortly prior to milking, each cow was presented with her calf. After suckling for a short period of time, the calf was tied to its mother' s forelegs while she was milked by a dairyman, after which the pair was released into an irregularly shaped corral of $6010 \mathrm{~m}^{2}$ where the observations took place. A few minutes after all the animals had been released into the corral, the cows and calves were separated from one another and allowed to graze in paddocks until the next ordenha. There was continuous surveillance of all animals as long as they were in the corral. All dam-offspring pairs were not observed for exactly the same amount of time $(\bar{x}=22.663 ; \sigma=9.898$ min per observation), as estimated by the time when a behavior involving a cow or her calf was first recorded, because all cows could not be milked simultaneously. There were nine observation sessions distributed over 10 days. Four of the sessions took place in the morning, and five in the afternoon. No session lasted $>55$ or $<25 \mathrm{~min}$.

Behavioral events were recorded on paper and with the aid of a tape recorder. The two behaviors of greatest interest were solicitation and acceptance, from which were derived the 17 primary variables analyzed later in this report. Solicitation denotes a calf approaching and apparently attempting to nurse from a cow by making head movements toward her udder. Acceptance occurred when a solicitation was successful for however short a period of time. Other behaviors, such as locomotion, resting and agonistic behavior, which could interfere with suckling, were recorded also. 


\section{RESULTS}

\section{Primary variables}

The primary variables under study and their corresponding letter designations are listed in Table 1. Tables 2 and 3 contain, respectively, statistical summaries of and correlations among the 17 variables. They are arranged in three categories as follows: (1) calf variables refer to initiations and outcomes of calves' attempts to nurse from cows; (2) cow variables involve solicitations that cows received and their responses to them; (3) dam-offspring variables are interactions between calves and their mothers. Letter subscripts to statistical tests presented in subsequent paragraphs of this report designate the corresponding variables listed in Table 1.

An uncontrolled variable that potentially could confound analyses of the behaviors of interest is the order of entry into the corral where the observations took place. That is, the observed behavioral variation might be attributable to nothing more than variation in the observers' opportunities to notice and record the animals' activities. Correlations coefficients between the number of minutes that the animals were available for observation, as conservatively estimated by the time when they were first mentioned in the recorded observations, and $\mathrm{O}$ (dam-offspring solicitations $(r=-0.083))$, I (non-filial solicitations $(r=-0.117))$, and L (total solicitations by calves $(r=-0.119)$ ) were low and statistically inconsequential (d.f. $=12 ; \mathrm{P}>0.50)$, suggesting that order of entry made no appreciable contribution to the observed behavioral variation. Correlation coefficients between minutes of observation and B (non-maternal solicitations $(\mathrm{r}=0.582))$ and $\mathrm{E}$ (total solicitations of cows $(\mathrm{r}=0.595))$ were statistically significant $($ d.f. $=12 ; 0.01<\mathrm{P}<0.05)$. The relative strength of these two correlations is attributable to outlier scores of two calves, which when eliminated from the data set reduced the respective values to $r=-0.076$ and $r=-0.079$ (d.f. 12; $P>0.50$ ), corroborating the previous interpretation that order of entry was not an important determinant of the observed behavioral variation, all scores of the two aberrant calves were left in the analyses that follow. 
Table 1. Letter designations, descriptive names, and definitions of the 17 primary variables under study

\begin{tabular}{|c|c|c|}
\hline \multirow{2}{*}{\multicolumn{2}{|c|}{$\begin{array}{l}\text { Variables } \\
\text { Calf variables }\end{array}$}} & \multirow[t]{2}{*}{ Descriptions } \\
\hline & & \\
\hline A & Cows solicited & Number of different cows solicited by individual calves \\
\hline $\mathrm{B}$ & Non-maternal solicitations & $\begin{array}{l}\text { Number of times that calves solicited cows that were not their own } \\
\text { mothers }\end{array}$ \\
\hline $\mathrm{C}$ & Non-maternal acceptances & $\begin{array}{l}\text { Number of times that calves nursed from cows that were not their } \\
\text { own mothers }\end{array}$ \\
\hline $\mathrm{D}$ & Non-maternal effectivenes & $\begin{array}{l}\text { The difference between non-maternal acceptances }(A c) \text { and } \\
\text { rejections }[R j=(S c-A c)] \text {, weighted by non-maternal solicitations } \\
(\mathrm{Sc}) \text {, or }(A c-R j)(A c+R j)\end{array}$ \\
\hline $\mathrm{E}$ & Total solicitations of cows & $\begin{array}{l}\text { Number of times that calves solicited their mothers and all other } \\
\text { cows }\end{array}$ \\
\hline $\mathrm{F}$ & Total acceptances by cows & $\begin{array}{l}\text { Number of times that calves nursed from their mothers and all other } \\
\text { cows }\end{array}$ \\
\hline G & Total calf effectiveness & $\begin{array}{l}\text { The difference between total acceptances and rerections by cows, } \\
\text { weighted by total solicitations of cows, as shown for Variable D, } \\
\text { above }\end{array}$ \\
\hline \multicolumn{3}{|c|}{ Cow variables } \\
\hline $\mathrm{H}$ & Soliciting calves & Number of different calves that solicited individual cows \\
\hline I & Non-filial solicitations & $\begin{array}{l}\text { Number of times that cows were solicited by calves that were not } \\
\text { their progeny }\end{array}$ \\
\hline $\mathrm{J}$ & Non-filial acceptances & $\begin{array}{l}\text { Number of times that cows nursed calves that were not their } \\
\text { progeny }\end{array}$ \\
\hline $\mathrm{K}$ & Non-filial effectiveness & $\begin{array}{l}\text { The difference between non-filial acceptances and rejections, } \\
\text { weghted by non-filial solicitations, as shown for Variable D, above }\end{array}$ \\
\hline $\mathrm{L}$ & Total solicitations by calves & $\begin{array}{l}\text { Number of times that cows that cows were solicited by their } \\
\text { progeny and all other calves }\end{array}$ \\
\hline M & Total acceptances of calves & $\begin{array}{l}\text { Number of times that cows nursed their progeny and all other } \\
\text { calves }\end{array}$ \\
\hline $\mathrm{N}$ & Total cow effectiveness & $\begin{array}{l}\text { The difference between total acceptances and rejections of calves, } \\
\text { weghted by total solicitations by calves, as shown for Variable D, } \\
\text { above }\end{array}$ \\
\hline \multicolumn{3}{|c|}{ Dam-offspring variables } \\
\hline $\mathrm{O}$ & Dam-offspring solicitations & Number of times that calves solicited their own mothers \\
\hline $\mathrm{P}$ & Dam-offspring acceptances & Number of times that cows nursed their own calves \\
\hline Q & Dam-offspring effectiveness & $\begin{array}{l}\text { The difference between the number of dam-offspring acceptances } \\
\text { and rejections, weghted by the number of dam-offspring } \\
\text { solicitations, as shown for Variable D, above }\end{array}$ \\
\hline
\end{tabular}


Table 2. Statistical summaries of the 17 primary variables under study

\begin{tabular}{llrr}
\hline & & $\bar{x}$ & $\sigma$ \\
\hline Calf Variables & & \\
A & Cows solicited & 6.00 & 3.25 \\
B & Non-maternal solicitations & 10.29 & 10.90 \\
C & Non-maternal acceptances & 5.57 & 6.87 \\
D & 3.71 & 16.10 \\
E & Non-maternal effectivenes & 20.29 & 10.43 \\
F & Total solicitations of cows & 14.07 & 6.16 \\
G & Total acceptances by cows & 74.57 & 24.45 \\
Cow variables & Total calf effectiveness & & \\
H & & 6.00 & 2.48 \\
I & Soliciting calves & 10.29 & 5.30 \\
J & Non-filial solicitations & 5.57 & 4.62 \\
K & Non-filial acceptances & 2.71 & 12.85 \\
L & Non-filial effectiveness & 20.29 & 6.39 \\
M & Total solicitations by calves & 14.07 & 5.28 \\
N & Total acceptances of calves & 71.79 & 31.82 \\
Dam-offspring variables & Total cow effectiveness & & \\
O & & 10.00 & 1.69 \\
P & Dam-offspring solicitations & 8.50 & 1.40 \\
Q & Dam-offspring acceptances & 70.86 & 24.30 \\
\hline
\end{tabular}

A SYSTAT principal components factor analysis (Wilkinson, 1987) was conducted. Factors whit Eigen value $>1$ were extracted and subjected to Equimax rolation. Four factors accounted for more than $95 \%$ of the variance with the fourth factor accounting for only $10.18 \pm 3.56 \%$. Inspection of twodimensional relationships among the variables when the factors were exhibited graphically suggested three easily discriminable clusters. The visual impression is consistent with the tree diagram presented in Fig. 1, which was obtained by the method of average linkage for $\mathrm{z}$ transformed variables. With two notable exceptions, i.e. G (total calf effectiveness), the clusters are coincident with the three categories of variables identified in Tables 1, 2 and 3, and Fig. 1 as calf, cow and dam-offspring variables. 
Table 3. Correlations coefficients among the 17 primary variables. Letter designations for the variables are explained in Table 1 . Values of $\pm 0.532,0.661$ and 0.780 are, respectively, statistically significant at the $0.05,0.01$ and 0.001 levels for a two-tailed test with d.f. $=12$

\begin{tabular}{|c|c|c|c|c|c|c|c|c|c|c|c|c|c|c|c|c|}
\hline & & & Calf v & riables & & & & & Cov & variab & & & & Da & $\begin{array}{l}\text { n-offsp } \\
\text { ariable }\end{array}$ & ing \\
\hline & B & $\mathrm{C}$ & $\mathrm{D}$ & $E$ & $\mathrm{~F}$ & $\mathrm{G}$ & $\mathrm{H}$ & I & $\mathrm{J}$ & $\mathrm{K}$ & $\mathrm{L}$ & $\mathrm{M}$ & $\mathrm{N}$ & $\mathrm{O}$ & $\mathrm{P}$ & $Q$ \\
\hline $\begin{array}{l}\text { Calf } \\
\text { variables }\end{array}$ & & & & & & & & & & & & & & & & \\
\hline A & 0.895 & 0.783 & 0.265 & 0.878 & 0.742 & -0.393 & -0.523 & -0.593 & -0.404 & -0.149 & -0.585 & -0.507 & -0.583 & -0.351 & -0.580 & -0.570 \\
\hline B & & 0.972 & 0.596 & 0.988 & 0.949 & -0.184 & -0.487 & -0.481 & -0.339 & -0.176 & -0.492 & -0.456 & -0.654 & -0.349 & -0.599 & -0.580 \\
\hline $\mathrm{C}$ & & & 0.744 & 0.958 & 0.983 & -0.063 & -0.444 & -0.434 & -0.338 & -0.222 & -0.455 & -0.451 & -0.672 & -0.357 & -0.586 & -0.556 \\
\hline $\mathrm{D}$ & & & & 0.573 & 0.742 & 0.338 & -0.183 & -0.197 & -0.175 & -0.186 & -0.244 & -0.256 & -0.486 & -0.305 & -0.386 & -0.322 \\
\hline $\mathrm{E}$ & & & & & 0.956 & -0.114 & -0.406 & -0.414 & -0.252 & -0.088 & -0.397 & -0.353 & -0.548 & -0.203 & -0.498 & -0.494 \\
\hline $\mathrm{F}$ & & & & & & 0.095 & -0.417 & -0.386 & -0.297 & -0.197 & -0.378 & -0.373 & -0.537 & -0.220 & -0.426 & -0.397 \\
\hline $\mathrm{G}$ & & & & & & & 0.107 & 0.199 & 0.105 & -0.032 & 0.293 & 0.284 & 0.560 & 0.484 & 0.725 & 0.782 \\
\hline $\begin{array}{l}\text { Cow } \\
\text { variables }\end{array}$ & & & & & & & & & & & & & & & & \\
\hline $\mathrm{H}$ & & & & & & & & 0.811 & 0.848 & 0.689 & 0.839 & 0.834 & 0.521 & 0.631 & 0.350 & 0.229 \\
\hline I & & & & & & & & & 0.866 & 0.633 & 0.975 & 0.890 & 0.575 & 0.550 & 0.433 & 0.330 \\
\hline $\mathbf{J}$ & & & & & & & & & & 0.900 & 0.901 & 0.969 & 0.588 & 0.630 & 0.353 & 0.221 \\
\hline $\mathrm{K}$ & & & & & & & & & & & 0.681 & 0.846 & 0.518 & 0.589 & 0.222 & 0.091 \\
\hline $\mathrm{L}$ & & & & & & & & & & & & 0.939 & 0.697 & 0.721 & 0.567 & 0.456 \\
\hline M & & & & & & & & & & & & & 0.763 & 0.760 & 0.574 & 0.455 \\
\hline $\mathrm{N}$ & & & & & & & & & & & & & & 0.834 & 0.938 & 0.885 \\
\hline $\begin{array}{l}\text { Dam- } \\
\text { offspring } \\
\text { variables }\end{array}$ & & & & & & & & & & & & & & & & \\
\hline $\mathrm{O}$ & & & & & & & & & & & & & & & 0.784 & 0.689 \\
\hline $\mathrm{P}$ & & & & & & & & & & & & & & & & 0.986 \\
\hline
\end{tabular}

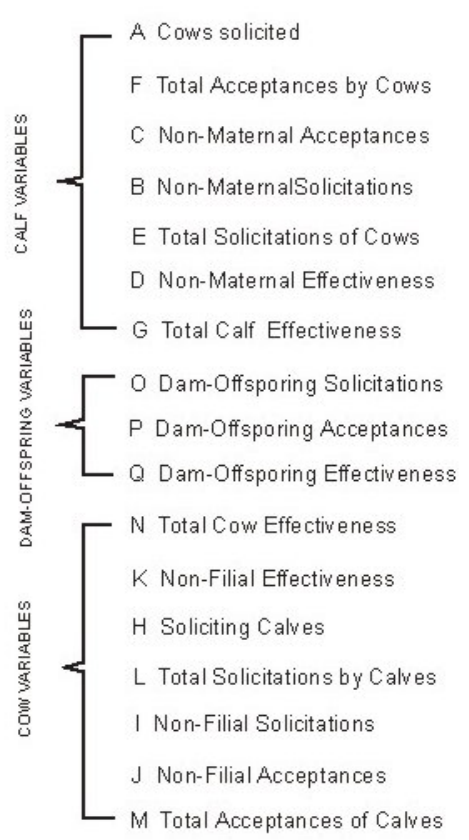

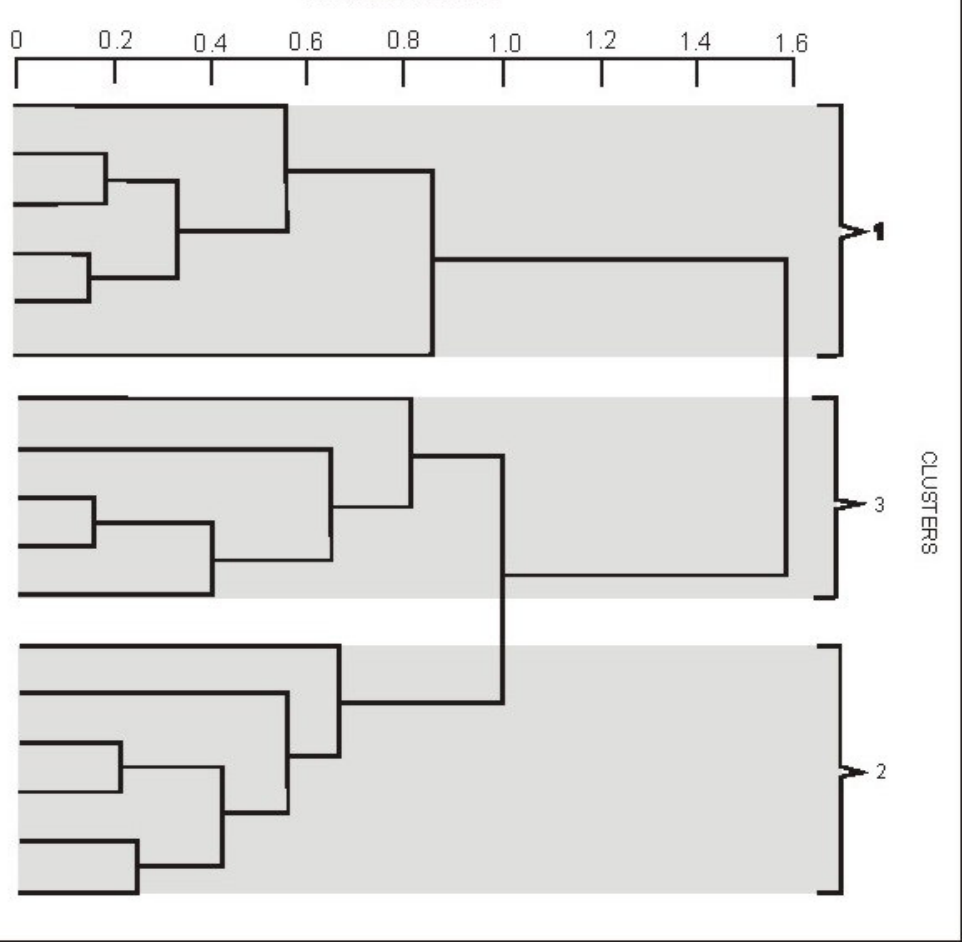

Figure 1. Tree diagram of inerrelaionships among the 17 variables

Every calf tried to nurse from its own mother more often than it did from any other individual cow. Although they approached their own mothers proportionately more often $(\bar{x}=0.493)$ than any one of the other 13 cows $(\bar{x}=0.039)$, the calves solicited nursing from their own mothers slightly less frequently than they did from all other cows combined 
$\left(t_{\mathrm{ob}}=0.097 ;\right.$ d.f. $\left.=26 ; \mathrm{P}>0.50\right)$. Calves were accepted at a slightly and insignificantly higher frequency by their own mothers than by all other cows combined $\left(\mathrm{t}_{\mathrm{p}} \mathrm{c}=1.562 ;\right.$ d.f. $=26 ; 0.10<\mathrm{P}$ $<0.20)$, and proportionately much more readily by their own mothers $(\bar{x}=0.604)$ than by any other individual cow $(\bar{x}=0.030)$. Calves were more effective, as defined in Table 1 , when they solicited nursing from their own mothers than when they went to other cows $\left(\mathrm{t}_{\mathrm{qd}}=12.925\right.$; d.f. $=$ 26; $\mathrm{p}<0.001$ ). It was common to see cows simultaneously nursing more than 1 , and sometimes as many as 4, calves, 1 of which was almost always her own progeny. Our data rarely permit the identification of the first calf to suckle in a multiple nursing bout.

Table 3 shows that with the exception of $G$, calf variables were negatively correlated with cow variables and dam-offspring variables. Among the calf variables it was positively correlated only with D (non-maternal effectiveness) ignoring its essentially zero correlation with $\mathrm{F}$ (total acceptances by cows). In contrast, cow variables were all positively correlated with each other, dam-offspring variables were positively correlated with one another and with $\mathrm{G}$. $\mathrm{G}$ and $\mathrm{N}$ were more related to dam-offspring variables than to their own a priori classifications, as shown in Fig. 1. There were large individual differences in accepting non-filial calves (inclusive range $=0-16$, $\bar{x}=5.571, \sigma=4.625)$. Cows were more likely to accept their own progeny than non-filial calves $\left(\mathrm{t}_{\mathrm{pj}}=2.267 ;\right.$ d.f. $\left.=26 ; \mathrm{P}<0.05\right)$, and filial solicitations were more effective than non-filial ones $\left(\mathrm{t}_{\mathrm{qk}}=9.275 ;\right.$ d.f. $\left.=26 ; \mathrm{P}<0.001\right)$.

\section{Reciprocal nursing}

There were 91 possible combinations of cows and non-filial calves. Every cow was solicited at least once by a non-filial calf. All but 1 of the cows allowed a non-filial calf to nurse at least once. Among the $144 \mathrm{~B}$ or I solicitations, 26 were reciprocal approaches to the others mother by 2 calves involving nine combinations of cows and non-filial calves. Four pairs of dams, involving 5 individual cows, reciprocally accepted the other member of the pair' s calf at least once. Two of the same cows rejected the other member of the pair's calf at least once. The four reciprocally accepting pairs, with individuals designated here by the letter $\mathrm{M}$ and a number. were M2-M3, M3M4, M4-M14 and M14-M17. Thus, there were no reciprocal triads, as would be the case, for example, if the reciprocally accepting pairs were M2-M3, M3-M4, and M4-M2, or M4-M14, M14-M17, and M17-M4. Three cows reciprocally rejected each other' s calves, but in one of those combinations, 1 cow accepted the other' $\mathrm{s}$ calf twice. In the remaining two combinations, 1 cow rejected and 1 accepted the other cow' s calf.

Overall, there was no difference between total acceptances and rejections within the reciprocal solicitations $\left(X^{2}=0.154\right.$; d.f. $\left.=1 ; 0.5<\mathrm{P}<0.75\right)$. Furthermore, if it is true that acceptances and rejections among reciprocal solicitations were distributed randomly, then the probability of reciprocal acceptances $\left(p^{2}\right)$ and reciprocal rejections $\left(q^{2}\right)$ should be equal, and the probability of 1 cow accepting and the other cow rejecting the soliciting calf should be $2(p q)$, which turned out to be the case $\left(X^{2}=0.256\right.$; d.f. $\left.=2 ; 0.25<\mathrm{P}<0.50\right)$ even though the value of $X^{2}$ was inflated because the expected frequencies were small. Calves were more likely to be accepted in non-reciprocal combinations $(\bar{x}=1.231 ; \sigma=1.067)$ than in reciprocal ones $(\bar{x}=0.778 ; \sigma=0.712)$, where $\mathrm{t}=2.026 ;$ d.f. $=68 ; \mathrm{P}<0.05$. Similarly, non-reciprocal solicitations $(\bar{x}=0.654 ; \sigma=4.759)$ were more effective than reciprocal ones $(\bar{x}=0.000 ; \sigma=2.806)$, where $\mathrm{t}=5.094 ;$ d.f. $=68 ; \mathrm{P}<0.001$. The effectiveness of pairs of calves reciprocally soliciting each other' $\mathrm{s}$ mother was negatively related $(\mathrm{P}=-0.587$; d.f. $=7 ; 0.05<\mathrm{P}<$ $0.10)$. 


\section{DISCUSSION}

Having been milked immediately before the observation sessions, every cow was presumably "dry", making it highly improbable that variation in milk availability affected the observed behavior. Similarly, the calves were deprived of food for the same amount of time before the ordenhas and, ignoring variation in body mass, activity, and other relevant factors, should have been "equally" hungry. Among the uncontrolled variables not examined were age, state of health, milk quality, stage of weaning, degree of kinship, familiarity among the animals, and sex of the calves, all of which must be investigated in order to achieve a better understanding of individual differences in the variables under discussion. Unavoidably, the variables that were controlled render suspect the generality of our results to free-ranging herds. For example, calves that were less milk deprived, that nursed from mothers with more milk in their udders, and that received greater rewards when they suckled, might not behave the same as the calves described here. Even so, it is easy to witness, as we have on numerous occasions, calves soliciting and being accepted by several cows under free-ranging conditions. At any rate, the present investigation suggests several new and specific hypotheses to be tested in future, more "natural" conditions.

\section{Primary variables}

The calves' attempts to nurse were not random. A calf was more likely to try to suckle from its own mother than from any other particular cow, but slightly more apt to solicit other cows in general. It is not surprising that soliciting and success in suckling from other cows was negatively related to frequency, acceptances, and effectiveness of a calf soliciting its own mother. Nonmaternal solicitation was positively associated with acceptance by other cows, but it tended to decrease the overall effectiveness of the calf' s strategy. That is, the more cows that a calf solicited, the greater the number of times that it succeeded in nursing, but the less likely it was to succeed on any given attempt. The calves behaved in such a way as to increase the absolute number of successes rather than behaving in accordance with the probability of rewards. In the context of choice theory (cf. Rachlin, 1989), and at the almost certain risk of oversimplifying (cf. Rachlin, 1978), the calves appeared to be more like "probabllity maximizers" than "probability matchers" Suppose, for example, that in a two-choice situation, Response $A\left(R_{A}\right)$ is rewarded $75 \%$ of the time and Response $B\left(R_{B}\right) 25 \%$. A "probability maximizer" would choose $R_{A} 100 \%$ of the time, thus receiving a reward $75 \%$ of the time over a series of trials. A "probability matcher" would choose $\mathrm{R}_{\mathrm{A}}$ on $75 \%$ and $\mathrm{R}_{\mathrm{B}}$ on $25 \%$ of the trials, committing one form of the "gambler' s fallacy" and being rewarded $0.75^{2}+0.25^{2}$ or $<63 \%$ of the time. The maximizing strategy was more pronounced in calves that were less successful with their own mothers.

Cows that rejected their own progeny tended to be avoided by and to reject non-filial calves. Cows that were solicited often by their own and by non-filial calves tended to accept them, and the calves' solicitations were worth the effort expended from the point of view of total acceptances and effectiveness of the solicitations. Those findings make intuitive sense inasmuch as calves should quickly learn to discriminate among cows that are likely to accept or reject them, while continuing to investigate the receptivity of other cows through the means of occasional solicitations.

It is interesting that calves were somewhat more likely to solicit non-maternal cows than their own mothers (and presumably would have nursed from whichever cow accepted them), while their mothers were more likely to nurse their own calves than non-fillal ones. One meaning of this finding is obvious: cows and calves have different motives. It is to the calves' advantage to get as much milk whenever and from whatever source they can, while their mothers' long-term interests are best served by not giving milk to calves other than their own progeny. It should be remembered that the calves' total success was determined by their interactions with all of the 
available cows, including their mothers. That leaves the question of why cows would accede to any non-filial solicitation, the answer to which is found in the well-known postulate of inclusive fitness theory to the effect that altruism should be practised to the extent to which it helps to perpetuate the genes of the altruist.

\section{Reciprocal nursing}

Owing to the lack of breeding records and appropriate serological or molecular analyses of Brazilian water buffalo, it was not possible to assess consanguinity among the subjects. Regardless of degree of kinship, which as Curaco and Brown (1986) pointed out is not essential for cooperative behavior, if it is true that altruism is ultimately advantageous for one individual it should be for others, and it should be reciprocated in groups where it exists. In our study, all but 1 cow allowed another' s calf to nurse, but we found no evidence that such "altruism" was reciprocal. When reciprocity occurred, its frequency was at a chance level, and it never involved $>2$ cows. Cows were just as apt to reject as to accept another cow' s calf reciprocally. Our failure to find reciprocity is consistent with investigations of the matter in other mammals (cf. Taylor and McGuire, 1988).

The absence of reciprocity does not negate the possibility that past kin-or group-selection had an effect on communal nursing, which in our subjects consisted of preferential treatment of the cows' own calves and frequent acceptance of other calves as well. Even so, if communal nursing is frequent but not reciprocal, its expression is probably unrelated to kinship. If it is advantageous to be a member of a herd, and if the herd cannot or need not be organized on the basis of genetic relatedness (cf. Murphey, 1990; Murphey and Duarte, 1990), a possible function of communal nursing of kin or nonkin is to strengthen social relationships in forming and maintaining herd integrity.

In conclusion, restricting milk availability to progeny appears to be a stronger motive than communal nursing in water buffalo cows. A calf, on the other hand, has no obvious reason to seek milk only from its own mother, although she is the most reliable source of nourishment. She may also be the most dependable provider of protection, hygienic care, social comfort, and orientation. Speculation regarding the origins and ultimate utility of communal nursing are beyond the scope of this report. Answering more proximate questions requires cognizance that communal nursing is not merely something that cows permit, nor is it entirely determined by the indiscriminate solicitations of hungry calves. Nursing, communal or not, is the outcome of simultaneous activities of cows and calves motivated by different needs and incentives that are, in turn, affected by unidentified individual state and trait differences.

\section{ACKNOWLEDGMENTS}

We thank Wagner Marchesi and his employees at the Fazenda Palestina, where the study took place, for their kind hospitality, assistance and tolerance. We greatly appreciate Dr. R. O. Goldthwaite' s contributions to the statistical analyses. Portions of this report were aided by funds from the Brazilian Government' Conselho Nacional de Pesquisa and the Funcação de Amparo a Pesquisa do Estado de São Paulo. Some of the information contained in this paper was presented at the 20th Annual Meeting of the Behavior Genetics Association, Aussois, France, 1990.

\section{REFERENCES}

Advisory Committee on Technology Innovation, 1981. The Water Buffalo: New Prospects for an Underutilized Animal. Report of an Ad Hoc Panel of the Advisory Committee on Technology Innovation, Board on Science and Technology for International Development, Commission on 
International Relations, National Research Council, National Academy Press, Washington, DC, $116 \mathrm{pp}$.

Associação Brasileira dos Criadores de Búfalo, undated. Bubalinocultura. Associação Brasileira dos Criadores de Búfalo, Sáo Paulo, 11 pp.

Caraco, T. and Brown, J. L., 1986. A game between communal breeders: when is food-sharing stable? J. Theor. Biol., 118: 379-393.

Das Graças Costa, A., Junqueira Franco, J. R., Junqueira, P. L. and Reis, R., 1971. Búfalo, Sinônimo de Carne, Leite, Manteiga e Trabalho para o Fomento da Pecuária Brasileira. Universidade Federal de Goiás, Goiânia, 39 pp.

Gittieman, J. L., 1985. Functions of communal care in mammals. In: M. Greenwood, P. H. Harvey and M. Slatkin, (Editors), Essays in Honour of John Maynard Smith. Cambridge University Press, Cambridge. 328 pp.

Herd, R. M., 1988. A technique for cross-mothering beef calves which does not affect growth. Appl. Anim. Behav, Sci., 19: 239-244.

Hudson, S.J., 1977. Multiple fostering of calves onto nurse cows at birth. Appl. Anim. Ethol., 3: 57-63.

Martin, P., 1984. The meaning of weaning. Anim, Behav., 32: 1257-1258.

Mendl, M. and Paul, E. S., 1989. Observation of nursing and sucking behaviour as an indicator of milk transfer and parental investment, Anim. Behav., 37: 513-515.

Murphey, R. M., 1990. Social aggregations in cattle, I. Segregation by breed in free-ranging herds. Behav. Genet., 20: 341-354.

Murphey, R. M. and Duarte, F. A. M. 1983. Calf control by voice command in a Brazilian dairy. Appl. Anim, Ethol., 11: 7-18.

Murphey, R. M. and Duarte, F. A. M. 1990. Social aggregations in cattle: II. Contributions of familiarity and genetic similarity. Behav. Genet. 20: 355-368.

Rachlin, H., 1978. A molar theory of reinforcement schedules. J. Exp. Anal, Behav., 30: 345360.

Rachlin, H., 1989. Judgement, Decision, and Choice, Freeman, New York, 288 pp.

Riedman, M. L., 1982. The evolution of alloparental care and adoption in mammals and birds. Rev. Biol., 57: 405-435.

Resecrans, J. G. and Hokemboken, W. D., 1982. Suckling activity and calf growth in a group of crossbred cows each rearing two foster calves. Appl.Anim. Ethol., 9: 131-140.

Taylor, C. E. and McGuire, M. T., 1988. Reciprocal altrusm: 15 years later. Ethol. Sociobiol., 9: 67-72.

Tulloich, D. G., 1979. The water buffalo, Bubalus bubalis, in Australia: Reproductive and parentoffspring behaviour. Aust. Wildl., 6: 265-287.

Wilkinson, L., 1987. Systat: The system of statistics (version 4). Systat Inc., Evanston, IL.

Wilson, E. O., 1975. Sociobiology, the neew synthesis. Harvard University Press, Cambridge, MA, 697 pp. 